\section{NASA needs more money to track asteroid threats}

NASA won't reach its mandated goal of tracking nearly all potentially hazardous near-Earth asteroids by 2020 with its current funding, according to an interim report published by the US National Research Council last week.

In 2005, the US Congress gave NASA a deadline of 2020 to detect, track and characterize $90 \%$ of near-Earth objects bigger than 140 metres. This is the size of objects thought to pose a significant risk if striking in urban areas, and at least twice the size of the object that levelled 2,000 square kilometres of Siberian forest in the 1908 Tunguska explosion.

The report, the final version of which is expected at the end of the year, says that the goal could be reached if more funding is found for future facilities, such as the Large Synoptic Survey Telescope or the Panoramic Survey Telescope and Rapid Response System (Pan-STARRS). It also cites the importance of the large Arecibo radar telescope in Puerto Rico, which is well suited to characterizing asteroids once they are found.

\section{World population will grow fastest in poorest areas}

The world's least-developed regions will double in population between now and 2050, from 828 million to 1.66 billion, predicts the non-profit Population Reference Bureau, based in Washington DC, in data published last week. These 49 countries, 33 of which are in Africa, have the lowest incomes, highest economic vulnerability and poorest humandevelopment indicators according to United Nations definitions.

The bureau's projections show that, over the same time period, the population of the world's more developed countries will creep up $7 \%$, from 1.23 billion to 1.32 billion - fuelled mainly by immigration from less-developed regions. In the United States, however, more than half of the

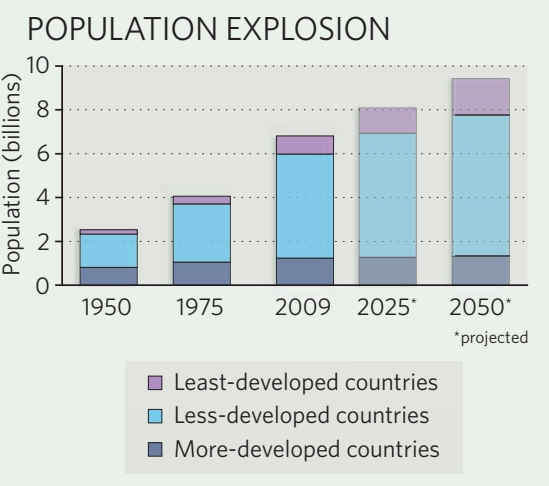

CLIMATE GLOOM

Reactions after slow progress at United Nations climate talks in Bonn, Germany, on 10-14 August

"If we don't have more movement and more consensus than we saw here, we won't have an agreement."

Jonathan Pershing, US lead climate negotiator.

"The best likely outcome in Copenhagen may be an interim agreement nailing down the basic architecture."

Elliot Diringer, vice-president of the Pew Center on Global Climate Change in Arlington, Virginia.

expected growth will be due to births there; it has one of the highest fertility rates in the developed world.

Worldwide, the population could hit 9.4 billion in 2050, up from 6.8 billion today and topping 7 billion in the latter half of 2011. By 2050, India will overtake China as the world's most populous country.

\section{Australia seeks carbon- reduction compromise}

Following last week's defeat in the Senate of his proposed scheme for reducing carbon emissions, Australian Prime Minister Kevin Rudd was this week hoping at least to spur billions of dollars of renewable-energy investment.

As Nature went to press, a law requiring $20 \%$ of Australia's energy to come from renewable sources by 2020 was expected to make its way through parliament.

The energy bill was delinked from a much broader legislative package that would use a cap-and-trade scheme to limit greenhouse-gas emissions from industry (see Nature 458, 554-555; 2009). But that was voted down by opposition politicians on 12 August. Rudd intends to re-submit the contentious emissions-trading scheme to Senate for voting before the end of the year.

\section{Innovation urged for water management in Asia}

Asian irrigation systems require urgent reform, according to a report published on 18 August by the International Water Management Institute in Battaramulla, Sri Lanka, together with the Food and Agriculture Organization of the United Nations and other partner groups.

Asia contains $70 \%$ of the world's irrigated land, much of it watered by statefunded canal systems that were installed in the 1970s. But the systems are poorly maintained. If Asia is to meet the needs of its growing population, the report says, it needs more efficient, better-regulated
"My fear is that we sign another agreement that doesn't have any teeth." Kevin Conrad, delegate from Papua New Guinea.

"It would be incomprehensible if this opportunity were lost."

Yvo de Boer, executive secretary of the United Nations Framework Convention on Climate Change.

Sources: New York Times, AP, Bloomberg, AFP

irrigation systems; more involvement by the private sector in managing them; and more education about, and investment in, watering programmes.

The report also suggests that governments should support and regulate extraction from groundwater aquifers by individual farmers, rather than condemn the practice.

For a longer version of this story, see http://tinyurl.com/news-2009-826

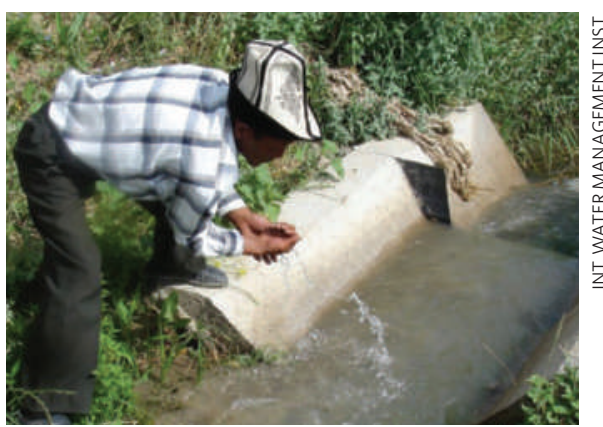

Canals in many Asian regions are in dire need of maintenance.

\section{Conflict of interest and resignation at drug agency}

The upper echelons of the US Food and Drug Administration (FDA) received unwanted attention last week. Daniel Schultz, head of the FDA's medical device division, resigned after allegations from employees that products were approved despite the concerns of agency scientists.

And it emerged that California-based Amphastar Pharmaceuticals had in April asked the FDA that Janet Woodcock, director of the FDA's Center for Drug Evaluation and Research, be removed from judging drug approvals of a generic blood-thinner because of her interactions with a competing firm, Momenta Pharmaceuticals, based in Cambridge, Massachusetts. Woodcock asked Momenta's co-founder, Ram Sasisekharan, to lead an FDA task force investigating tainted Chinese-made heparin last year, and she and Momenta scientists then co-authored medical journal articles on the topic. The FDA is looking into the complaints. 